\title{
The quest to make fully functional human pancreatic beta cells from embryonic stem cells: climbing a mountain in the clouds
}

\author{
James D. Johnson ${ }^{1}$ \\ Received: 18 March 2016 / Accepted: 23 June 2016 / Published online: 29 July 2016 \\ (C) Springer-Verlag Berlin Heidelberg 2016
}

\begin{abstract}
The production of fully functional insulin-secreting cells to treat diabetes is a major goal of regenerative medicine. In this article, I review progress towards this goal over the last 15 years from the perspective of a beta cell biologist. I describe the current state-of-the-art, and speculate on the general approaches that will be required to identify and achieve our ultimate goal of producing functional beta cells. The need for deeper phenotyping of heterogeneous cultures of stem cell derived islet-like cells in parallel with a better understanding of the heterogeneity of the target cell type(s) is emphasised. This deep phenotyping should include high-throughput single-cell analysis, as well as comprehensive 'omics technologies to provide unbiased characterisation of cell products and human beta cells. There are justified calls for more detailed and well-powered studies of primary human pancreatic beta cell physiology, and I propose online databases of standardised human beta cell responses to physiological stimuli, including both functional and metabolomic/proteomic/ transcriptomic profiles. With a concerted, community-wide effort, including both basic and applied scientists, beta cell replacement will become a clinical reality for patients with diabetes.
\end{abstract}

Electronic supplementary material The online version of this article (doi:10.1007/s00125-016-4059-4) contains a slideset of the figures for download, which is available to authorised users.

James D. Johnson

james.d.johnson@ubc.ca

1 Diabetes Research Group, Life Sciences Institute, Department of Cellular and Physiological Sciences, University of British Columbia, 5358-2350 Health Sciences Mall, Vancouver, BC, Canada V6T 1 Z3
Keywords Embryonic stem cells · Glucose-stimulated insulin release $\cdot$ Human pancreatic islet beta cells $\cdot$ Review

\section{Abbreviation \\ PDX1 Pancreatic and duodenal homeobox 1}

\section{The case for beta cell replacement in diabetes}

Diabetes mellitus was recognised early in the era of regenerative medicine research as an obvious indication for a stem cell based therapy. Type 1 diabetes results from the loss of more than $80 \%$ of an individual's pancreatic beta cells, while type 2 diabetes occurs when there is insufficient functional beta cell mass to meet the body's needs. The replacement of lost or dysfunctional beta cells in all patients that require it is one of the most important, but elusive, goals of diabetes research. The rationale for beta cell replacement is clear, given the success with which islet cell transplants reduce dangerous hypoglycaemic events and slow the progression of complications [1-3]. Pancreatic beta cells have evolved as master regulators of metabolic homeostasis, sensing glucose and other nutrients and releasing appropriate insulin to induce their storage. We understand the basics of beta cell biology, especially the ionic mechanisms underlying insulin release in response to large and abrupt glucose stimuli, which include a rapid rise in cytosolic $\mathrm{Ca}^{2+}$ subsequent to the metabolismdriven closure of $\mathrm{K}_{\mathrm{ATP}}$ channels, as well as a plethora of coupling factors [4]. However, we do not understand precisely how human beta cells respond to physiological stimuli and make fate decisions.

There are a number of possible ways to replace beta cells in patients with diabetes. Beta cell proliferation could theoretically be induced from the few remaining beta cells in people 
with type 1 diabetes [5]. Intense efforts are underway to unlock the secrets of beta cell proliferation, but no growth factors or drugs have yet been shown to robustly and selectively increase beta cell proliferation in humans without significant safety concerns. Beta cell growth could theoretically be stimulated from a dormant population of pancreatic stem cells, but there is little in vivo evidence that these exist, despite promising ex vivo/in vitro data [6]. The conversion of non-beta cells into beta cells has also been proposed as a possible source of new cells [7, 8], but most of the relevant data are in young rodents, which exhibit plasticity in response to pancreatic injury that is lost with age and generally absent in humans [9]. Direct evidence of cell-type interconversion, for example using live imaging, will be required to supplement Cre-Lox lineage tracing, which relies on short promoter elements that are potentially promiscuous. All of these regenerative therapies appear to be far over the horizon, with considerable obstacles to be surmounted.

A pinnacle of regenerative medicine would be the creation of beta cell replacements that appropriately sense a broad array of nutrients and secrete insulin exactly as primary beta cells do. In this article, I review progress towards this goal and speculate on the way forward. I use the analogy of climbing a mountain, where the summit is a population of fully functional pancreatic beta cells that recapitulate the complete range of cellular functions that healthy human beta cells exhibit (Fig. 1). However, the top of the mountain is shrouded in cloud as we, collectively, still do not understand exactly how normal human beta cells behave. I recognise that some will argue that a diabetes treatment does not require cells that behave exactly as bona fide beta cells, but it is my opinion that nothing short of a virtual phenocopy of mature beta cells will provide a moment-to-moment response to glucose and other nutrients that exceeds the capabilities of the most sophisticated artificial pancreases.

I write this article from the perspective of a beta cell biologist involved in testing human stem cell derived 'beta-like' cells for multiple groups over a 15 year timespan. I have seen both excitement and heartbreak up-close. However, my laboratory has not been directly involved in protocol design or the production of beta-like cells and I have no academic or financial stake in the outcome of this research. My aim is to see these efforts proceed directly and with the highest degree of rigour for the benefit of the patients who depend on this work.

This article focuses on key issues around the assessment of in vitro derived beta cell replacements, and does not delve deeply into the specific differences in various stem cell differentiation protocols, which are reviewed elsewhere (e.g. [3, $10-15])$. The current review is limited to efforts to generate beta cells from embryonic stem cells, but most of what is discussed is applicable to efforts to generate beta cells from induced pluripotent cells. Other cell sources are now generally seen as redundant, given the relative ease of obtaining stem cells from adult tissue biopsies. The obstacles to the development and testing of beta-like cells are basically the same, regardless of the source of the starting material.

\section{A brief history of attempts to make beta cells from scratch}

The history of directed differentiation towards a beta cell fate, like all cutting-edge fields, is one of fits and starts. Because of
Fig. 1 Climbing a mountain in the clouds. Approximate timeline of efforts to derive beta cell surrogates from embryonic stem cells, including key milestones

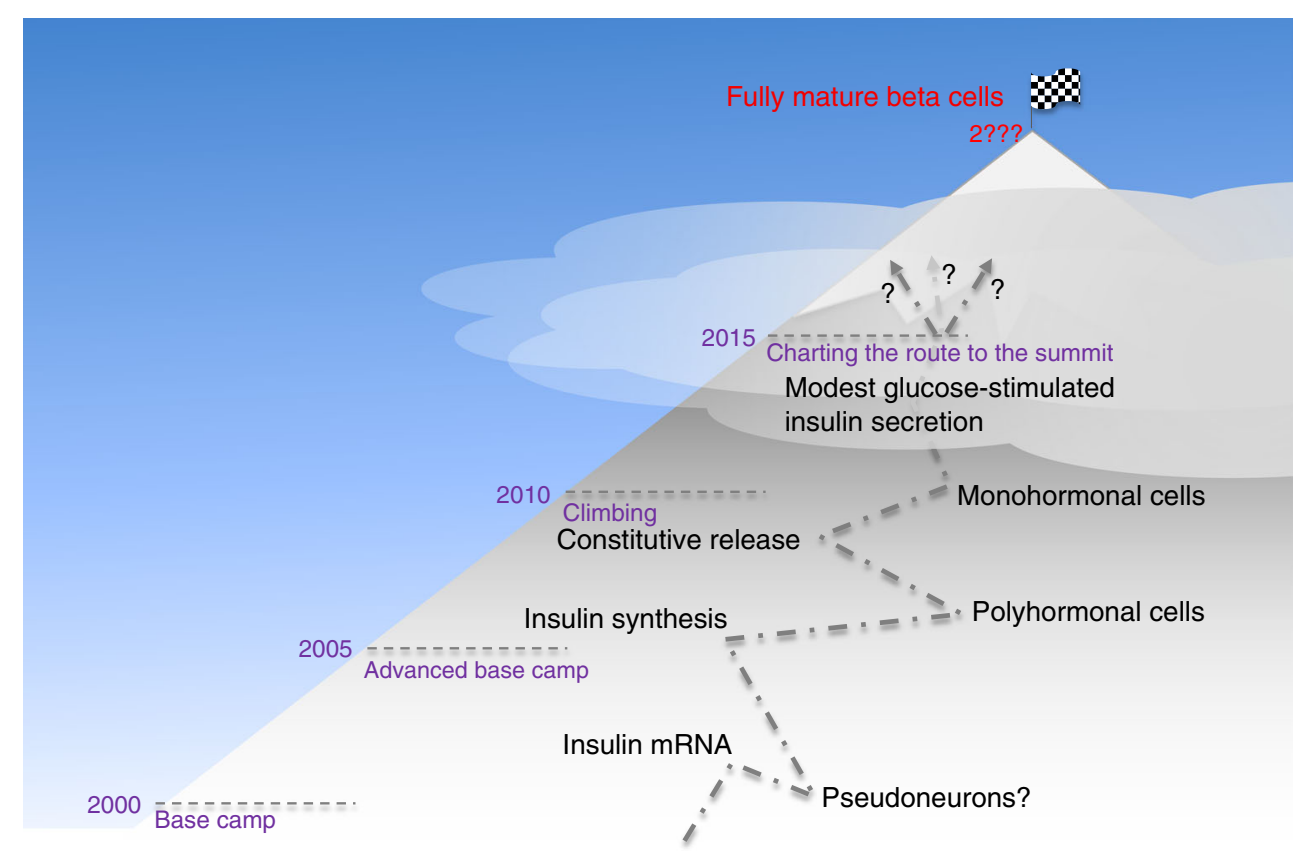


space constraints, it is not possible to detail here all of the reports of beta-like cells in the literature. In addition, many large-scale studies have been undertaken by commercial entities, meaning that the extent of the efforts that have led us to this point might never be made public. Key papers reflective of the major eras of research in this field are highlighted throughout this review and shown in Table 1. For the purpose of this review, eras are defined by the achievement of: (1) detectable insulin mRNA; (2) detectable insulin protein production and constitutive secretion; and (3) the measurement of modest regulated insulin secretion from monohormonal cells. These eras correspond to major evolutions in the logic and experimental approaches used to derive beta-like cells (Fig. 1).

\section{The insulin mRNA expression and insulin immunoreacti-} vity era ( 2000-2004) At the beginning of a mountain climb, there can be ups and downs before the best route to ascend becomes clear. It has been over 15 years since the first reports of efforts to generate beta cells from stem cells. The field was initiated with attempts using mouse stem cells and cellselection approaches [16-18], as well as spontaneous differentiation and identification of insulin-producing cells with approaches that included staining with the zinc-binding dye dithizone [19]. As an example of the former approach, Soria et al characterised cells from mouse embryonic stem cell cultures isolated via a neomycin-resistance cassette under the control of human INS regulatory elements [20]. Kim and colleagues improved differentiation by adding growth inhibitors [21]. Both groups presented evidence of improved glucose control in diabetic mice. Early studies employed PCR to identify insulin mRNA, often via methods that would not be considered adequately quantitative today, so it is unclear how much insulin mRNA was present per cell compared with primary beta cells. Early insulin mRNA measurements were typically expressed as a fold change relative to embryonic stem cells; however, insulin mRNA in stem cells is essentially zero,

Table 1 Milestones towards the in vitro production of beta-like cells

\begin{tabular}{|c|c|c|c|c|c|c|c|c|c|}
\hline \multirow[t]{2}{*}{ Key reports } & \multicolumn{3}{|c|}{ Insulin production } & \multicolumn{2}{|l|}{ In vivo } & \multicolumn{4}{|c|}{ In vitro glucose response/insulin release } \\
\hline & $\begin{array}{l}\text { Insulin } \\
\text { mRNA }\end{array}$ & $\begin{array}{l}\text { Insulin } \\
\text { protein } \\
\text { synthesis }\end{array}$ & $\begin{array}{l}\text { Insulin } \\
\text { only }^{\mathrm{a}}\end{array}$ & $\begin{array}{l}\text { Diabetes } \\
\text { reversal }^{\text {b }}\end{array}$ & $\begin{array}{l}\text { Insulin } \\
\text { secretory } \\
\text { index }^{\mathrm{c}}\end{array}$ & $\begin{array}{l}\text { Insulin } \\
\text { secretory } \\
\text { index }\end{array}$ & $\begin{array}{l}\text { Rapid } \\
\text { response }\end{array}$ & Response $^{\mathrm{f}}$ & $\begin{array}{l}\text { Low- } \\
\text { glucose } \\
\text { shut-off }\end{array}$ \\
\hline $\begin{array}{l}\text { Primary beta cells } \\
{[40,49,50,72]}\end{array}$ & $100 \%$ & $100 \%$ & $\sim 100 \%$ & $1-7$ days & $\begin{array}{l}200- \\
400 \%\end{array}$ & $\begin{array}{l}200- \\
1200 \%\end{array}$ & Yes & $\sim 100 \%$ & Yes \\
\hline Rezania, 2014 [40] & $100 \%$ & $\sim 100 \%$ & $89 \%$ & 40 days & $200 \%$ & $170 \%$ & No & $10 \%$ & No \\
\hline Pagliuca, 2014 [42] & $?$ & $\sim 100 \%$ & $77 \%$ & $?$ & $171 \%$ & $220 \%$ & $?$ & $50 \%$ & $?$ \\
\hline Russ, 2015 [44] & $90 \%$ & Present $^{\mathrm{nq}}$ & $97 \%$ & No & 0 & $200 \%$ & $?$ & $?$ & $?$ \\
\hline Basford, 2012 [32] & $2 \%$ & Present $^{\mathrm{nq}}$ & No & $?$ & $?$ & No & No & $?$ & $?$ \\
\hline Hori, 2002 [21] & Present $^{\mathrm{nq}}$ & Present $^{\mathrm{nq}}$ & $?$ & Partial & $?$ & $?$ & Yes? & $?$ & $?$ \\
\hline Assady, 2001 [22] & Present $^{\mathrm{nq}}$ & $?$ & $?$ & $?$ & $?$ & $?$ & $?$ & $?$ & $?$ \\
\hline \multicolumn{10}{|c|}{$\begin{array}{l}\text { Early mouse embryonic stem } \\
\text { cell studies }\end{array}$} \\
\hline Soria, 2000 [20] & Present $^{\mathrm{nq}}$ & $?$ & $?$ & 7 days & $300 \%^{\mathrm{nq}}$ & $?$ & Yes? ${ }^{\mathrm{nq}}$ & $?$ & $?$ \\
\hline Lumelsky, 2001 [18] & Present $^{\mathrm{nq}}$ & ? & No & No & ? & $\sim 400 \%{ }^{\mathrm{nq}}$ & Yes? ${ }^{\mathrm{nq}}$ & ? & ? \\
\hline
\end{tabular}

Prominent examples from the different eras of research towards the in vitro directed differentiation of human embryonic stem cells into beta cells are listed, along with an assessment of their properties relative to primary beta cells (shown in blue type). Two early mouse embryonic stem cell studies are also shown. Observations are derived from the data in the publications and include the benefits of hindsight. Green denotes a similarity to human beta cells; yellow denotes a partially achieved goal; and red denotes failure

${ }^{a}$ Negligible expression of glucagon and somatostatin (i.e. monohormonal)

${ }^{\mathrm{b}}$ Glucose-stimulated insulin release dynamics measured by perifusion

${ }^{c}$ Based on in vivo challenge of transplanted cells with glucose at the time when diabetes reversal was achieved

${ }^{\mathrm{d}}$ Based on static incubation (some with a parallel design, some with a sequential design)

${ }^{\mathrm{e}}$ Percentage of cells responding to glucose, using $\mathrm{Ca}^{2+}$ responses as a surrogate

${ }^{\mathrm{f}}$ In some studies, recipient mice were hyperglycaemic but not frankly diabetic

${ }^{\mathrm{g}}$ The length of glucose stimulation varied in these studies; shut off is expected to be more common with short durations of high glucose

?, not assessed, not reported or not clear; nq, present, but not quantified to today's standards 
so it was easy to obtain a large relative increase. In the mountaineering analogy, the production of small amounts of insulin mRNA is equivalent to reaching base camp (Fig. 1).

In the early 2000 s, studies reported that cells with insulin immunoreactivity spontaneously arose in adherent or suspension cultures of human or mouse embryonic stem cells [18, 22]. Many early studies were influenced by parallel efforts to differentiate neurons. There was an emphasis on expanding cells that were positive for nestin, an intermediate filament protein enriched in neuronal progenitors. However, lineagetracing studies subsequently found that nestin is dispensable in the natural development of primary beta cells [23]. In fact, these early efforts probably generated mixed cultures including neuron-like cells that produced small amounts of insulin, perhaps related to the insulin-producing cells in the central nervous system we and others reported [24, 25]. For example, Lumelsky et al reported the production of apparent beta-like cells from mouse stem cells using a protocol that selected for nestin-positive cells [18]. Remarkably, they reported an approximately fourfold increase in insulin secretion after only $5 \mathrm{~min}$ of high-glucose stimulation, although this was a static incubation experiment with only two replications [18]. Given that 3-5 min are required to change the ATP/ADP ratio sufficiently to close $\mathrm{K}_{\text {ATP }}$ channels in beta cells (Fig. 2), the finding of ultra-fast insulin release was probably the result of variability in the static incubation procedure itself. Static experiments require more replicates because technical variation is high, as lysed beta cells in the supernatant fraction can easily give the illusion of insulin release. Careful studies have demonstrated that most, if not all, of the insulin immunoreactivity in those early preparations was associated with the ability of embryonic stem cells to take up fluorescently labelled insulin from their media [26, 27].

The initial era of discovery in this field was thus marked by the expression of insulin mRNA in stem cell derived cultures. This was a breakthrough, as the INS gene is only expressed at levels that can sustain circulating insulin protein by a single cell type: the pancreatic beta cell. In some studies, stem cell derived cells were reported to be glucose responsive in vitro and to reverse diabetes in mice, but the lack of robust human insulin measurements and the benefit of hindsight make clear that this was not the summit of the mountain, but rather the beginning of the climb.

\section{The insulin protein synthesis and constitutive secretion era} ( 2005-2013) The insulin production era was marked by an emphasis on mimicking what was known at the time about pancreatic embryology and islet cell development [11]. This era was also associated with a shift towards the use of defined culture conditions. Decades of research on islet development employing multiple model systems guided efforts to generate beta cells through multi-staged processes, with clear signposts, that first focused on the production of pancreatic and duodenal homeobox 1 (PDX1)-positive pancreatic endoderm. For example, Micallef et al used mouse embryonic stem cells expressing green fluorescent protein driven by the endogenous PDX1 promoter and found important roles for retinoic acid in differentiation [28].

A California-based company, NovoCell (now ViaCyte), was also guided by developmental biologists and published a series of papers describing their efforts to coax human embryonic stem cells towards a beta cell fate. In 2005, this company published its recipe for producing near-homogeneous cultures of definitive endoderm and defining key markers that many in the field use as signposts of the developing pancreatic lineage [29]. In 2006, this company climbed further along this path, documenting the generation of cells in which C-peptide and proinsulin, as well as key transcription factors, were quantified at the protein level [30]. However, while cells derived from this protocol could respond to direct depolarisation with $\mathrm{KCl}$, they were unable to respond to elevated glucose with the appropriate increase in insulin secretion [30], meaning that these cells contained a basic complement of ion channels, but lacked the coupling of glucose influx to electrical activity. This assertion is also supported by transcriptomic profiling of similarly differentiated human embryonic stem cells conducted by Hrvatin et al [31], but a detailed examination of ion-channel subunit pairing at the protein level is missing from the field.

From 2006 to the present, many groups reported protocols that produced cells that were responsive to direct depolarisation, but not to high glucose concentrations [32, 33]. These immature cells often produced more than one hormone $[32,34,35]$, observations that led to the re-examination of human pancreatic development $[31,35]$. Despite the lack of regulated hormone secretion, the in vitro generation of polyhormonal cells capable of synthesising robust quantities of insulin protein represented our arrival at an advanced basecamp (Fig. 1).

Clearly, something was missing from the recipe. With the idea that the final stages of differentiation could be completed more naturally in vivo, several groups pursued a strategy of transplanting PDX1-positive progenitor cells. In 2008, ViaCyte published the results of studies in which 'stage 4' pancreatic progenitor cells were transplanted into nondiabetic SCID-beige mice [36]. While these data were not subjected to robust statistical treatment, some of the transplanted mice did exhibit higher human C-peptide levels $30 \mathrm{~min}$ after a $20 \mathrm{~h}$ fast, suggesting the possibility of regulated insulin secretion. Examples were provided to illustrate that these transplants could protect mice from streptozotocininduced hyperglycaemia once the progenitor cells had developed for several months in vivo [36]. Furthermore, dynamic 

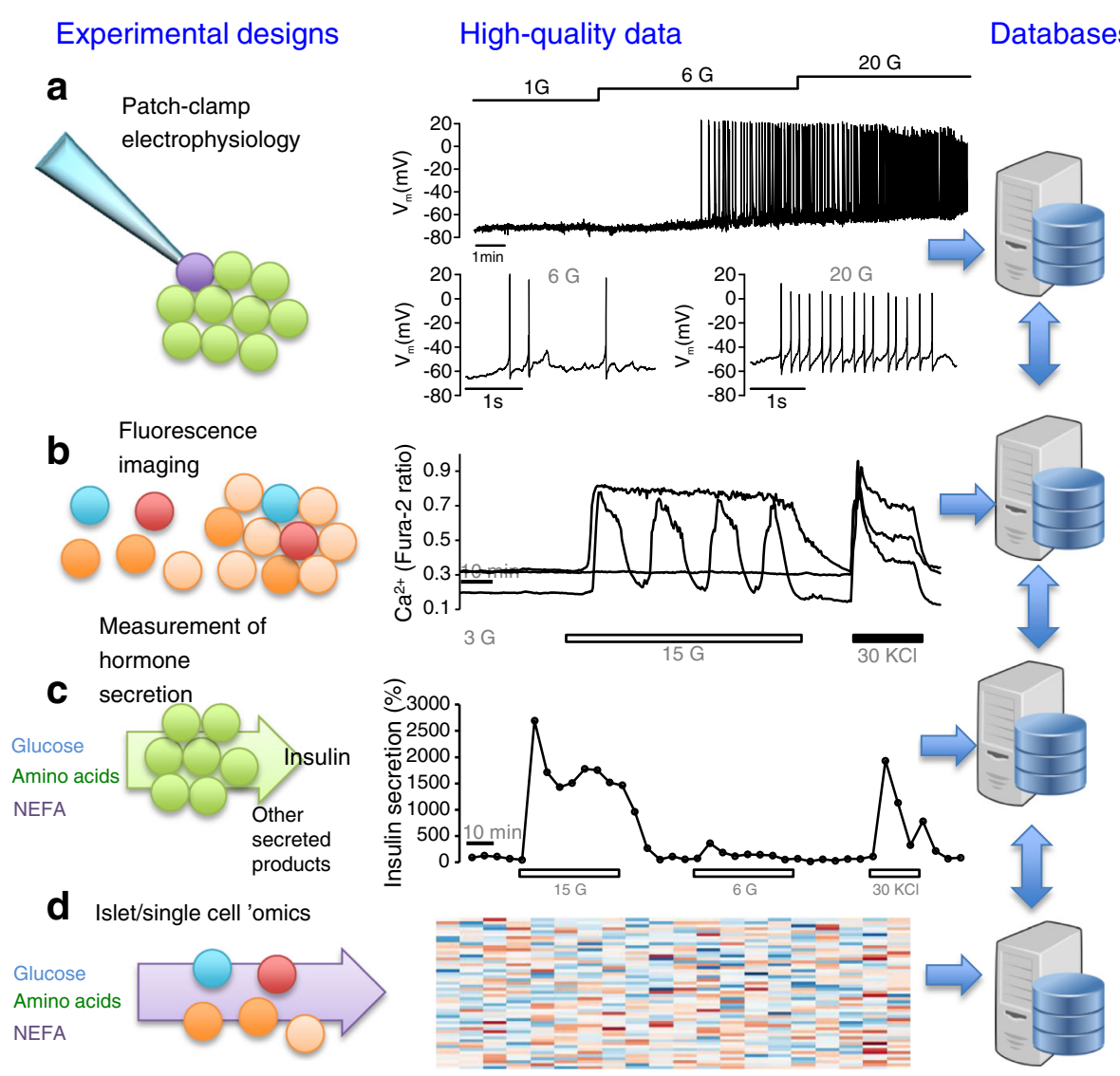

Fig. 2 Basic dynamic assays of beta cell function. Experimental configurations are shown to the left: (a) patch-clamp electrophysiology to assess membrane currents and membrane potential oscillations in single beta cells; (b) imaging with fluorescent dyes or genetically engineered probes to assess second-messenger response and response heterogeneity of single beta cells and islets; (c) dynamic measurements of hormone secretion in response to multiple classes of nutrients; (d) islet or single-cell transcriptomic, proteomic and metabolomic responses to nutrients compared with genomic sequencing. Examples of high-quality human islet cell data are aso shown: (a) glucose-induced plasma membrane voltage

perifusion studies demonstrated glucose-dependent insulin secretion from removed grafts, although the responses were approximately one-third of those of the human islets they used for comparison [37].

While somewhat anecdotal, these promising data paved the way for a clinical trial testing the approach of progenitor cell transplantation (see below). Janssen's BetaLogics group, together with Kieffer and colleagues at the University of British Columbia, also showed that transplanted pancreatic progenitor cells resolved over time in the in vivo environment into monohormonal cells [38]. Interestingly, this group recently reported differences in progenitor cell maturation between immunodeficient mouse and rat transplant recipients, confirming that the host plays an important role in beta-like cell differentiation, but also implying the potential for unwanted variability among human hosts [39]. In 2014, ViaCyte oscillations of a single beta cell within an intact islet (unpublished trace courtesy of Q. Zhang and P. Rorsman, University of Oxford, UK); (b) single cell Fura-2 cytosolic calcium imaging of three cells from dispersed human islets [41]; (c) insulin secretion measurements from perifused intact human islets (Johnson lab unpublished data); and (d) a theoretical example of a heat map generated from 'omics or genetic studies. Ideally, data obtained from experts in these specific techniques would be shared and searchable online, such that investigators in the stem-cell-derivation field can benefit from this collective expertise

received United States Food and Drug Administration approval for a Phase I/II trial (NCT02239354) to test the safety, cell survival and insulin secretion of a product called VC-01, which combines progenitor cells (PEC-01) and a macroencapsulation device called Encaptra. According to ClinicalTrials.gov, the study will be completed in August 2017 and will enrol 40 people of ages $18-55$ years. The relative merits of transplanting progenitor cells vs mature cells have been reviewed [3, 14]. Laboratories around the world are continuing towards the goal of producing mature beta cells in culture that synthesise meaningful amounts of insulin and secrete it appropriately in response to physiological glucose increases.

The glucose-stimulated insulin secretion era ( 2014-present) In 2014, the field climbed upwards with a publication 
from the BetaLogics/ University of British Columbia group, in which islet biologists from my team recorded the first cellularlevel evidence of glucose responsiveness in stem cell derived cells. Specifically, a small minority of beta-like cells exhibited calcium responses after a step-wise increase from 3 to $20 \mathrm{mmol} / 1$ glucose, although the responses to this superphysiological challenge were far smaller, slower and rarer than what we observe in batches of healthy human islets $[40,41]$. These 'stage 7 ' cells also generally failed to inactivate their calcium responses, which is an essential feature of mature beta cells that prevents hypoglycaemia in the postprandial state. Nevertheless, cells responded to elevated glucose with increased insulin secretion, although this was significantly delayed and reduced in dynamic perifusion studies when compared with human islets [40]. When transplanted into a streptozotocin-induced mouse model of diabetes, a relatively small number of these cells reversed diabetes after 40 days [40]. In vivo glucose-responsive insulin secretion was surprisingly modest at a time when diabetes had been fully reversed. The simplest interpretation of this finding is that basal insulin release was mostly responsible for reversing diabetes in the mice that received transplants.

At around the same time, Pagliuca and colleagues in the Melton group published work on a similar protocol, producing what they called SC- $\beta$ cells [42]. Presumably due to space constraints, some caveats of these data were not discussed at the time. For example, the authors studied in vitro insulin secretion of SC- $\beta$ cells using an unusual assay consisting of sequential $30 \mathrm{~min}$ static incubations of 2 and $20 \mathrm{mmol} / \mathrm{l} \mathrm{glu}-$ cose. A statistically significant increase in average insulin secretion at 2 and $20 \mathrm{mmol} / 1$ glucose was observed in pooled data from human embryonic and induced pluripotent stem cell studies. The reproducibility between cultures is difficult to determine from the examples shown, and from the box and whisker plots used for quantification. Ideally, the SC- $\beta$ cells should have been compared with higher-quality human islets, as the preparations they used were non-functional according to their assay. The authors also examined intracellular calcium levels with the non-ratiometric dye Fluo-4 and reported that responses were observed in a majority of SC- $\beta$ cells, which is the most positive report to date. However, individual traces of the calcium responses were not provided, leaving the reader unable to assess cellular behaviour or compare them with bona fide beta cells, which would have allowed an assessment of functional heterogeneity. Gene-expression analysis showed that cultures of these cells bore a close molecular resemblance to human islets when a subgroup of 100 genes was assessed after microarray. Importantly, glucose-responsive insulin secretion was reported from SC- $\beta$ cells 2 weeks after transplantation into immunocompromised mice that were presumably non-diabetic. When transplanted into NRG-Akita mice, SC- $\beta$ cells exhibited variable and modest glucose-stimulated insulin secretion and prevented the gradual progression to diabetes in this model, although it was not shown in this paper that SC- $\beta$ cells could treat pre-existing diabetes to a statistically significant extent. A 2016 follow-up paper reported that encapsulated SC- $\beta$ cells could reverse hyperglycaemia in streptozotocin-injected C57BL/6 mice [43]; however, the transient effects of this beta cell toxin can make interpretation difficult without removal of the graft. This work, which has also been reviewed by multiple experts [3, 10, 12-15], is an important advance and, together with the work from BetaLogics/University of British Columbia, provides the first convincing evidence of glucose responsiveness from human embryonic stem cell derived cells in vitro. Additional studies are required to convincingly show that these in vitro derived cells respond in a quantitatively similar manner to healthy human primary cells.

Since the BetaLogics/ University of British Columbia and Melton group papers in 2014, there has been a lull in the publication of new protocols. In 2015, Russ et al reported insulinproducing cells that showed limited glucose responsiveness after transplantation [44]. There was no dynamic analysis of insulin secretion or signal transduction in these cells and the transplant recipients still became diabetic, although slightly less so [44]. One gets the sense that the field is now recalibrating its expectations and has stopped to chart a route to the summit (Fig. 1). Both of the 2014 landmark papers made use of highthroughput screening, and although this is a powerful technique, some might wonder whether it has taken us off the path of mimicking pancreas development. Despite this concern, high-throughput efforts to identify factors that increase insulin production and promote beta cell differentiation continue in our group and elsewhere [45].

\section{Where are we now?}

We are now in the steepest part of the climb, and the clouds surrounding the summit are thick. At this moment, stem cell derived beta-like cells are probably the functional equivalent of the best-characterised human and rodent beta cell lines [46]. In my opinion, clear evidence has not yet been presented that fully functional beta cells can be found in stem cell derived cultures. Many industrial and academic groups around the world, some in 'stealth mode', continue to chase this goal. Now it is important to pause on the trail to chart the most efficient route to the summit. It is essential to critically consider whether the bar for beta cell functionality is high enough and whether the methods for assessing this are sufficient.

The assessment of beta cell functionality has not been standardised. With different groups emphasising the importance of different assays, it is difficult to directly compare differentiation protocols. In vivo tests of beta cell functionality vary between groups, and even within publications from the same group. It is not clear what level of in vivo glucose responsiveness is sufficient for therapeutic efficacy, or if a mixed-meal 
response might be a more realistic assessment tool. A more basic question is whether transplantation should be considered the sole gold standard for testing beta cell functionality. While in vivo tests of beta-like cell functionality will always be a critical step towards the clinic, the transplantation of insulin pellets with constant insulin release is remarkably effective at reversing diabetes in mice [47], so I would argue that this assay is a low bar as it is currently implemented. Indeed, maturing stem cell derived grafts achieve normoglycaemia in mice well before even minimal glucose-responsive C-peptide release is evident [3]. Clearly, clinical cell therapy for diabetes must outperform pellets that constantly release insulin regardless of nutrient status. To demonstrate such superiority, it is likely that a battery of more sensitive and rigorous in vivo tests will be required, including i.v. rapidly sampled tests of insulin secretion in response to glucose and other nutrients at physiologically relevant concentrations.

The in vitro assays of beta cell functionality used in the field are also not adequate to define the maturity state of engineered beta cell surrogates. The field must move towards standardised and rigorous tests of dynamic insulin secretion in response to multiple stimuli, and these responses should be compared with many batches of high-quality human islets and take into account how beta cell function changes over a lifetime. There are still many examples in the literature of papers that lack the key controls required to demonstrate the physiological function of stem cell derived cells. Importantly, the expectations for functionality for in vitro differentiated cells should be higher than for isolated beta cells, which are necessarily studied in a state of postisolation/culture stress. Insulin immunoreactivity must be shown to be actual insulin, produced and released from within these cells in a manner similar to that observed for beta cells.

\section{Remaining obstacles — standardised assessment of the target cell phenotype?}

Some mountains have more than one peak. Without accurate charting and carefully calibrated instruments it can be difficult to know which is the true summit. Unfortunately, at this point we understand too little about the function and functional heterogeneity of human beta cells [48], and how the latter matches the cellular heterogeneity of stem cell derived cultures. Despite islet-distribution initiatives, few laboratories have unfettered, immediate access to high-quality, researchgrade human islets, so the study of human islets lags behind that of rodent models. When human islets are available for research they are of varying quality, with most preparations rejected for clinical use. A number of factors make isolated islets a non-ideal model for human islets in vivo. Beyond the fact that islets are separated from their niche, including vasculature and innervation, the processes of human pancreas procurement and isolation are prolonged and brutal compared with the techniques used for obtaining rodent islets. The responsiveness of human islet preparations varies widely depending on donor age and health status, warm or cold ischaemia, and isolation, transportation and culture, to name just a few variables $[49,50]$. Once isolated, human islets are studied with varying rigor and in studies that are almost always underpowered. Currently, each batch of new human embryonic stem cell derived product is compared with a handful of contemporaneous human islet preparations, regardless of their quality, which can lead to spurious results.

A number of initiatives could help solve the problem of low-quality human islet data, which limits our ability to define target cell behaviour. First, it will be important to increase support for groups producing high-quality human islets for research purposes, including centres producing islets exclusively for research [49]. Second, it will be important to move towards a set of standardised tests for human beta cell functionality (Fig. 2). This does not preclude the use of additional assays specific to distinct research questions, but it is imperative that human islets are functionally comparable between laboratories. Third, I propose the creation of an online resource from which islet biologists and stem cell biologists can leverage functional data from hundreds of human islet preparations (Fig. 2), much in the way that bioinformaticians query geneexpression data [51, 52]. This could be linked to existing and emerging 'omics databases, including the islet biology components of the Human Diabetes Proteome Project (www.hdpp. info). We have recently published a reference dataset of human islet calcium responses to glucose, and new statistical analysis approaches to analyse this type of data [41]. With access to robust and abundant functional human islet data, islet biologists will be able to form a more complete picture of human islet and beta cell heterogeneity. Stem cell biologists can aim for a specific range of functionality and compare generated cells with ideal or near-ideal human islets in silico.

\section{Remaining obstacles-deep phenotyping}

In order to achieve our collective goal, unbiased deep phenotyping of both human beta cells and human embryonic stem cell derived cultures will be required (Fig. 2). Transcriptomic or partial transcriptomic analyses have already been used to guide differentiation efforts in recent studies [40, 42], but these efforts must be more robust and extended to include proteomics, metabolomics and epigenetics. Transcriptome, proteome and metabolome analyses should be conducted under a variety of experimental conditions to understand the plasticity of in vitro derived cells (and of human beta cells) (Fig. 2). Perhaps the most exciting emerging areas of research are the realms of single-cell transcriptomics and single-cell proteomics, which will complement the expression databases 
already present from sorted and whole intact islets. While depth and coverage remain technical hurdles, these approaches will soon shed much-needed light on the functional heterogeneity of human islet cell subtypes and states, as well as the variability observed in in vitro derived cultures. Although insulin is by far the major secreted product of primary beta cells, this cell type likely expresses hundreds of other secreted proteins [52], several of which have known physiological roles [52-54]. Future studies should also address the completeness of insulin processing, as it is possible that improperly processed and/or secreted insulin can provoke or accelerate beta cell directed autoimmunity [55].

Single-cell functional analysis can also be improved upon, whether they are focused on dispersed cells or on a cell-level analysis of intact islets (which retain key cell-cell contacts $[56,57])$. Calcium imaging has the drawback that, while glucose stimulates calcium signals in beta cells, some factors can increase calcium without appreciable effects on insulin release, making it an imperfect surrogate. Electrophysiological characterisation should be routine in every study, expanding upon research carried out by Wheeler and colleagues [32]. Tools are available for optical imaging of voltage responses, which enables high-throughput analyses of thousands of cells and will therefore likely supplant traditional electrophysiology for the characterisation of in vitro derived cells. Highthroughput electrophysiology and lab-on-a-chip technologies will be particularly useful in both understanding the phenotypic range of human islet cells and assessing their in vitro differentiated counterparts side by side [58-60]. The islet biologists and mathematical modellers who are most familiar with these aspects of beta cell behaviour should be engaged in studies of in vitro differentiated cells to dissect the properties of all of the major ion currents, the shape of the action potentials and the distinctive bursting patterns that are normally seen in healthy beta cells (Fig. 2). It is notable that the vast majority of mechanistic research on beta cell function has focused on the response to glucose, typically at only high concentrations (15-20 mmol/l), but it will be important to determine how in vitro derived cells respond to all relevant nutrients and hormones at physiologically relevant concentrations. A 'human beta cell project' could combine comprehensive omic mapping of human islet cell types, under multiple physiological states, with high-throughput imaging-based analyses of morphological and functional behaviours. Some of this information is already published and available, but it would need to be expanded and aggregated into a public resource (e.g. T1DBase) in a manner through which stem cell derived surrogates could be compared automatically.

Deep phenotyping should be employed on multiple complementary models. CRISPR and other genome-editing tools will soon permit mechanistic interrogation of non-human primates and other large animal models, as well as stem cells. In vitro studies will be augmented by inserting reporters into stem cell genomes [61] and by non-invasive imaging [62]. Moreover, in vitro culture systems can be designed to mimic the in vivo situation, including the intricate three-dimensional structure of the developing islet and/or pancreas. Similarly, perfused cultures may be employed to precisely control the build up of cellular waste and paracrine factors. For example, insulin itself limits beta cell mass expansion during development $[63,64]$. Clearly, ever-more powerful discovery research will continue to guide efforts to generate fully functional human beta cells in culture. In other words, advanced technology will help us see through the clouds to find the true summit.

\section{Remaining obstacles—beyond beta cell generation}

Once the field eventually produces the functional equivalent of primary human pancreatic beta cells, a crucial obstacle will be to protect these cells from the stresses associated with transplantation, especially prior to complete engraftment, and recurrent autoimmunity in people with type 1 diabetes $[12,65]$. Some have argued that this will be impossible with fully functional beta cells, and that less mature products will be more robust at withstanding the stresses associated with transplantation and recurrent immunity. In either case, immunoisolation is being proposed as a method to protect cell products from host immunity. Immunoisolation strategies to prevent autoimmune destruction roughly fall into three categories: macro-encapsulation with devices; microencapsulation with materials such as alginate; and so-called device-less encapsulation, which seeks to identify immune-privileged transplant sites $[12,43,66]$. However, all of these approaches necessarily place the grafted cells further from the blood source, creating the possibility of a relatively hypoxic environment. Unfortunately, primary pancreatic beta cells are unusually susceptible to hypoxic stress, when compared with other cell types and with subdifferentiated pancreatic progenitor cells. Moreover, we have recently shown that production of insulin itself inherently leads to endoplasmic reticulum stress [67]. It is therefore likely that in vitro derived cells synthesising equivalent hormone levels will be similarly fragile and will exhibit increased apoptosis in response to cytokines released from cytotoxic T cells. One possibility would be to engineer cells to produce proinsulin that has been modified to be less antigenic or to produce less insulin at key times [68]. Perhaps the ultimate cure for type 1 diabetes will require islet cell replacement with designer cells in conjunction with targeted therapies to suppress local autoimmunity. In addition to type 1 diabetes, it is possible that stem cell derived beta cells might prove useful as a treatment for type 2 diabetes and other conditions associated with beta cell dysfunction [69].

While a comprehensive discussion is beyond the scope of this article, there is also considerable debate concerning the 
ideal transplantation site. Virtually all sites will be unable to mimic portal vein access to the liver, and will lack native innervation and vasculature. However, the initial functionality obtained with current human islet transplant protocols suggests that these concerns do not preclude success [12].

\section{Outlook}

It takes a lot of resources and very expensive gear to climb at the highest altitudes. Indeed, many smaller groups are exiting the race to develop better differentiation protocols, while large and medium-sized entities are carrying on. I believe that a successful therapy will require mature beta cells, regardless of their fragility, that provide fully physiological nutrient on and off responses, given that fasting hyperinsulinaemia may be linked to cardiovascular risk and obesity $[25,70,71]$.

There is currently a strong push to get more trials of human embryonic stem cell derived cells into the clinic. For example, 2015 saw the launch of Semma Therapeutics, based in Cambridge, Massachusetts, to commercialise the progress made by the Melton group. In February 2016, ViaCyte disclosed that it had found markers of insulin-containing cells within sentinel devices implanted into the diabetic volunteers in its Phase I/II clinical trial. It remains to be shown whether the insulin levels in the explanted devices are quantitatively equivalent to those produced by human beta cells and whether the cells respond to relevant secretagogues. It should be noted that if these beta-like cells are proliferating a rate higher than $1 \%$ then it is likely that they are not fully differentiated [46, 67]. Nevertheless, this progress has precipitated a major consolidation in the field, with the merger of the Janssen subsidiary BetaLogics with ViaCyte (which was also supported by Janssen prior to the merger).

So, what is the role for academic laboratories in this sphere? Undoubtedly, many groups are continuing efforts to advance protocol design, but it is prohibitively expensive for some to reproduce today's status quo. Instead, many academic laboratories are employing existing protocols to generate beta-like cells for studies of human development and to answer other questions where a fully functional endproduct is not required. Indeed, there will be explosive growth in the use of human embryonic stem cell derived or induced pluripotent stem derived beta-like cell models for physiology, disease modelling and toxicology in the near future.

Acknowledgements F. Lynn (University of British Columbia), P. MacDonald (University of Alberta), J. Bruin (Carleton University), and T. Kieffer (University of British Columbia) are thanked for carefully reading the manuscript and providing helpful advice. Q. Zhang and P. Rorsman (Oxford University) are thanked for providing an example electrophysiological trace for Fig. 2.
Funding Related research in the author's laboratory is support by the JDRF.

Duality of interest The author declares that there is no duality of interest associated with this manuscript.

Contribution statement The author was the sole contributor to the article and takes full responsibility for its contents.

\section{References}

1. Ryan EA, Paty BW, Senior PA et al (2005) Five-year follow-up after clinical islet transplantation. Diabetes 54:2060-2069

2. Thompson DM, Meloche M, Ao Z et al (2011) Reduced progression of diabetic microvascular complications with islet cell transplantation compared with intensive medical therapy. Transplantation 91:373-378

3. Bruin JE, Rezania A, Kieffer TJ (2015) Replacing and safeguarding pancreatic $\beta$ cells for diabetes. Sci Transl Med 7:316ps323

4. Misler S, Barnett DW, Gillis KD, Pressel DM (1992) Electrophysiology of stimulus-secretion coupling in human $\beta$-cells. Diabetes 41:12211228

5. Keenan HA, Sun JK, Levine J et al (2010) Residual insulin production and pancreatic $\beta$-cell turnover after 50 years of diabetes: Joslin Medalist Study. Diabetes 59:2846-2853

6. Smukler SR, Arntfield ME, Razavi R et al (2011) The adult mouse and human pancreas contain rare multipotent stem cells that express insulin. Cell Stem Cell 8:281-293

7. Chera S, Baronnier D, Ghila L et al (2014) Diabetes recovery by age-dependent conversion of pancreatic $\delta$-cells into insulin producers. Nature 514:503-507

8. Thorel F, Nepote V, Avril I et al (2010) Conversion of adult pancreatic $\alpha$-cells to $\beta$-cells after extreme $\beta$-cell loss. Nature 464: $1149-1154$

9. Kushner JA (2013) The role of aging upon $\beta$ cell turnover. J Clin Invest 123:990-995

10. Kushner JA, MacDonald PE, Atkinson MA (2014) Stem cells to insulin secreting cells: two steps forward and now a time to pause? Cell Stem Cell 15:535-536

11. Pagliuca FW, Melton DA (2013) How to make a functional $\beta$-cell. Development 140:2472-2483

12. Bartlett ST, Markmann JF, Johnson P et al (2016) Report from IPITA-TTS opinion leaders meeting on the future of $\beta$-cell replacement. Transplantation 100(Suppl 2):S1-S44

13. Dominguez-Bendala J, Lanzoni G, Klein D, Alvarez-Cubela S, Pastori RL (2016) The human endocrine pancreas: new insights on replacement and regeneration. Trends Endocrinol Metab 27: 153-162

14. Quiskamp N, Bruin JE, Kieffer TJ (2015) Differentiation of human pluripotent stem cells into $\beta$-cells: potential and challenges. Best Pract Res Clin Endocrinol Metab 29:833-847

15. Hanley N (2014) Closing in on pancreatic beta cells. Nat Biotechnol 32:1100-1102

16. Leon-Quinto T, Jones J, Skoudy A, Burcin M, Soria B (2004) In vitro directed differentiation of mouse embryonic stem cells into insulin-producing cells. Diabetologia 47:1442-1451

17. Soria B (2001) In-vitro differentiation of pancreatic $\beta$-cells. Differentiation 68:205-219

18. Lumelsky N, Blondel O, Laeng P, Velasco I, Ravin R, McKay R (2001) Differentiation of embryonic stem cells to insulin-secreting structures similar to pancreatic islets. Science 292:1389-1394 
19. Shiroi A, Yoshikawa M, Yokota $\mathrm{H}$ et al (2002) Identification of insulin-producing cells derived from embryonic stem cells by zinc-chelating dithizone. Stem Cells 20:284-292

20. Soria B, Roche E, Berna G, Leon-Quinto T, Reig JA, Martin F (2000) Insulin-secreting cells derived from embryonic stem cells normalize glycemia in streptozotocin-induced diabetic mice. Diabetes 49:157-162

21. Hori Y, Rulifson IC, Tsai BC, Heit JJ, Cahoy JD, Kim SK (2002) Growth inhibitors promote differentiation of insulin-producing tissue from embryonic stem cells. Proc Natl Acad Sci U S A 99: $16105-16110$

22. Assady S, Maor G, Amit M, Itskovitz-Eldor J, Skorecki KL, Tzukerman M (2001) Insulin production by human embryonic stem cells. Diabetes 50:1691-1697

23. Treutelaar MK, Skidmore JM, Dias-Leme CL et al (2003) Nestinlineage cells contribute to the microvasculature but not endocrine cells of the islet. Diabetes 52:2503-2512

24. Sipione S, Eshpeter A, Lyon JG, Korbutt GS, Bleackley RC (2004) Insulin expressing cells from differentiated embryonic stem cells are not beta cells. Diabetologia 47:499-508

25. Mehran AE, Templeman NM, Brigidi GS et al (2012) Hyperinsulinemia drives diet-induced obesity independently of brain insulin production. Cell Metab 16:723-737

26. McKiernan E, Barron NW, O’Sullivan F, Barham P, Clynes M, O'Driscoll L (2007) Detecting de novo insulin synthesis in embryonic stem cell-derived populations. Exp Cell Res 313:1405-1414

27. Hansson M, Tonning A, Frandsen U et al (2004) Artifactual insulin release from differentiated embryonic stem cells. Diabetes 53: 2603-2609

28. Micallef SJ, Janes ME, Knezevic K, Davis RP, Elefanty AG, Stanley EG (2005) Retinoic acid induces Pdx1-positive endoderm in differentiating mouse embryonic stem cells. Diabetes 54:301305

29. D'Amour KA, Agulnick AD, Eliazer S, Kelly OG, Kroon E, Baetge EE (2005) Efficient differentiation of human embryonic stem cells to definitive endoderm. Nat Biotechnol 23:1534-1541

30. D'Amour KA, Bang AG, Eliazer S et al (2006) Production of pancreatic hormone-expressing endocrine cells from human embryonic stem cells. Nat Biotechnol 24:1392-1401

31. Hrvatin S, O'Donnell CW, Deng F et al (2014) Differentiated human stem cells resemble fetal, not adult, $\beta$ cells. Proc Natl Acad Sci U S A 111:3038-3043

32. Basford CL, Prentice KJ, Hardy AB et al (2012) The functional and molecular characterisation of human embryonic stem cell-derived insulin-positive cells compared with adult pancreatic beta cells. Diabetologia 55:358-371

33. Takeuchi H, Nakatsuji N, Suemori H (2014) Endodermal differentiation of human pluripotent stem cells to insulin-producing cells in 3D culture. Sci Rep 4:4488

34. Nostro MC, Sarangi F, Ogawa $\mathrm{S}$ et al (2011) Stage-specific signaling through TGF $\beta$ family members and WNT regulates patterning and pancreatic specification of human pluripotent stem cells. Development 138:861-871

35. Bruin JE, Erener S, Vela J et al (2014) Characterization of polyhormonal insulin-producing cells derived in vitro from human embryonic stem cells. Stem Cell Res 12:194-208

36. Kroon E, Martinson LA, Kadoya K et al (2008) Pancreatic endoderm derived from human embryonic stem cells generates glucoseresponsive insulin-secreting cells in vivo. Nat Biotechnol 26:443452

37. Motte E, Szepessy E, Suenens K et al (2014) Composition and function of macroencapsulated human embryonic stem cellderived implants: comparison with clinical human islet cell grafts. Am J Physiol Endocrinol Metab 307:E838-E846

38. Bruin JE, Rezania A, Xu J et al (2013) Maturation and function of human embryonic stem cell-derived pancreatic progenitors in macroencapsulation devices following transplant into mice. Diabetologia 56:1987-1998

39. Bruin JE, Asadi A, Fox JK, Erener S, Rezania A, Kieffer TJ (2015) Accelerated maturation of human stem cell-derived pancreatic progenitor cells into insulin-secreting cells in immunodeficient rats relative to mice. Stem Cell Rep 5:1081-1096

40. Rezania A, Bruin JE, Arora P et al (2014) Reversal of diabetes with insulin-producing cells derived in vitro from human pluripotent stem cells. Nat Biotechnol 32:1121-1133

41. Wills QF, Boothe T, Asadi A et al (2016) Statistical approaches and software for clustering islet cell functional heterogeneity. Islets 8 : 48-56

42. Pagliuca FW, Millman JR, Gurtler M et al (2014) Generation of functional human pancreatic $\beta$ cells in vitro. Cell 159:428-439

43. Vegas AJ, Veiseh O, Gürtler M et al (2016) Long-term glycemic control using polymer-encapsulated human stem cell-derived beta cells in immune-competent mice. Nat Med 22:306-311

44. Russ HA, Parent AV, Ringler JJ et al (2015) Controlled induction of human pancreatic progenitors produces functional beta-like cells in vitro. EMBO J 34:1759-1772

45. Szabat M, Modi H, Ramracheya R et al (2015) High-content screening identifies a role for $\mathrm{Na}^{+}$channels in insulin production. R Soc Open Sci 2:150306

46. Scharfmann R, Pechberty S, Hazhouz Y et al (2014) Development of a conditionally immortalized human pancreatic $\beta$ cell line. J Clin Invest 124:2087-2098

47. Korsgren E, Korsgren O (2016) Glucose effectiveness: the mouse trap in the development of novel $\beta$-cell replacement therapies. Transplantation 100:111-115

48. Rutter GA, Pullen TJ, Hodson DJ, Martinez-Sanchez A (2015) Pancreatic $\beta$-cell identity, glucose sensing and the control of insulin secretion. Biochem J 466:203-218

49. Lyon J, Manning Fox JE, Spigelman AF et al (2016) Researchfocused isolation of human islets from donors with and without diabetes at the Alberta Diabetes Institute IsletCore. Endocrinology 157:560-569

50. Street CN, Lakey JR, Shapiro AM et al (2004) Islet graft assessment in the Edmonton Protocol: implications for predicting long-term clinical outcome. Diabetes 53:3107-3114

51. van de Bunt M, Manning Fox JE, Dai X et al (2015) Transcript expression data from human islets links regulatory signals from genome-wide association studies for type 2 diabetes and glycemic traits to their downstream effectors. PLoS Genet 11:e1005694

52. Yang YH, Szabat M, Bragagnini C et al (2011) Paracrine signalling loops in adult human and mouse pancreatic islets: netrins modulate beta cell apoptosis signalling via dependence receptors. Diabetologia 54:828-842

53. Yang YH, Manning Fox JE, Zhang KL, MacDonald PE, Johnson JD (2013) Intraislet SLIT-ROBO signaling is required for beta-cell survival and potentiates insulin secretion. Proc Natl Acad Sci U S A 110:16480-16485

54. Yang YH, Wills QF, Johnson JD (2015) A live-cell, high-content imaging survey of 206 endogenous factors across five stress conditions reveals context-dependent survival effects in mouse primary beta cells. Diabetologia 58:1239-1249

55. Vomund AN, Zinselmeyer BH, Hughes J et al (2015) Beta cells transfer vesicles containing insulin to phagocytes for presentation to T cells. Proc Natl Acad Sci U S A 112:E5496-E5502

56. Halban PA, Wollheim CB, Blondel B, Meda P, Niesor EN, Mintz DH (1982) The possible importance of contact between pancreatic islet cells for the control of insulin release. Endocrinology 111:86-94

57. Benninger RK, Head WS, Zhang M, Satin LS, Piston DW (2011) Gap junctions and other mechanisms of cell-cell communication regulate basal insulin secretion in the pancreatic islet. J Physiol 589:5453-5466 
58. Nourmohammadzadeh M, Xing Y, Lee JW et al (2016) A microfluidic array for real-time live-cell imaging of human and rodent pancreatic islets. Lab Chip 16:1466-1472

59. Pedraza E, Karajic A, Raoux M et al (2015) Guiding pancreatic beta cells to target electrodes in a whole-cell biosensor for diabetes. Lab Chip 15:3880-3890

60. Yi L, Wang X, Dhumpa R, Schrell AM, Mukhitov N, Roper MG (2015) Integrated perfusion and separation systems for entrainment of insulin secretion from islets of Langerhans. Lab Chip 15:823-832

61. Liu H, Yang H, Zhu D et al (2014) Systematically labeling developmental stage-specific genes for the study of pancreatic $\beta$-cell differentiation from human embryonic stem cells. Cell Res 24: $1181-1200$

62. Konorov SO, Schulze HG, Gage BK et al (2015) Process analytical utility of Raman microspectroscopy in the directed differentiation of human pancreatic insulin-positive cells. Anal Chem 87:1076210769

63. Ye L, Robertson MA, Mastracci TL, Anderson RM (2016) An insulin signaling feedback loop regulates pancreas progenitor cell differentiation during islet development and regeneration. Dev Biol 409:354-369

64. Duvillie B, Currie C, Chrones T et al (2002) Increased islet cell proliferation, decreased apoptosis, and greater vascularization leading to $\beta$-cell hyperplasia in mutant mice lacking insulin. Endocrinology 143:1530-1537
65. Vendrame F, Pileggi A, Laughlin E et al (2010) Recurrence of type 1 diabetes after simultaneous pancreas-kidney transplantation, despite immunosuppression, is associated with autoantibodies and pathogenic autoreactive CD4 T cells. Diabetes 59:947-957

66. Hoesli CA, Raghuram K, Kiang RL et al (2011) Pancreatic cell immobilization in alginate beads produced by emulsion and internal gelation. Biotechnol Bioeng 108:424-434

67. Szabat M, Page MM, Panzhinskiy E et al (2016) Reduced insulin production relieves endoplasmic reticulum stress and induces $\beta$ cell proliferation. Cell Metab 23:179-193

68. Nakayama M, Abiru N, Moriyama $\mathrm{H}$ et al (2005) Prime role for an insulin epitope in the development of type 1 diabetes in NOD mice. Nature 435:220-223

69. Bruin JE, Saber N, Braun N et al (2015) Treating diet-induced diabetes and obesity with human embryonic stem cell-derived pancreatic progenitor cells and antidiabetic drugs. Stem Cell Rep 4:605-620

70. ACCORD Study Group (2016) Nine-year effects of 3.7 years of intensive glycemic control on cardiovascular outcomes. Diabetes Care 39:701-708

71. Shanik MH, Xu Y, Skrha J, Dankner R, Zick Y, Roth J (2008) Insulin resistance and hyperinsulinemia: is hyperinsulinemia the cart or the horse? Diabetes Care 31(Suppl 2):S262-S268

72. Johnson JD, Ao Z, Ao P et al (2009) Different effects of FK506, rapamycin, and mycophenolate mofetil on glucose-stimulated insulin release and apoptosis in human islets. Cell Transplant 18:833-845 